\title{
Bernard Barbiche, Christian Sorrel (dir.), La France et le concile Vatican II. Actes du colloque de La Courneuve (Centre des archives diplomatiques). 9 novembre 2012
}

Avant-propos de Frédéric Baleine du Laurens.

Bruxelles, P. I. E. Peter Lang, coll. « Diplomatie et Histoire », vol. 20, 2013, $264 \mathrm{p}$.

Notes, bibliographie, illustrations hors texte.

Paul Airiau

\section{(2) OpenEdition} Journals

Édition électronique

URL : http://journals.openedition.org/assr/26296

DOI : $10.4000 /$ assr.26296

ISSN : $1777-5825$

Éditeur

Éditions de l'EHESS

Édition imprimée

Date de publication : 31 décembre 2014

Pagination : 118

ISBN : 978-2-7132-2467-6

ISSN : 0335-5985

Référence électronique

Paul Airiau, « Bernard Barbiche, Christian Sorrel (dir.), La France et le concile Vatican II. Actes du colloque de La Courneuve (Centre des archives diplomatiques). 9 novembre 2012 », Archives de sciences sociales des religions [En ligne], 168 | 2014, mis en ligne le 02 avril 2015, consulté le 22 septembre 2020. URL : http://journals.openedition.org/assr/26296 ; DOI : https://doi.org/10.4000/ assr.26296

Ce document a été généré automatiquement le 22 septembre 2020.

(C) Archives de sciences sociales des religions 


\section{Bernard Barbiche, Christian Sorrel (dir.), La France et le concile Vatican II. Actes du colloque de La Courneuve (Centre des archives diplomatiques). 9 novembre 2012}

Avant-propos de Frédéric Baleine du Laurens.

Bruxelles, P. I. E. Peter Lang, coll. « Diplomatie et Histoire », vol. 20, 2013, $264 \mathrm{p}$.

Notes, bibliographie, illustrations hors texte.

Paul Airiau

\section{RÉFÉRENCE}

Bernard Barbiche, Christian Sorrel (dir.), La France et le concile Vatican II. Actes du colloque de La Courneuve (Centre des archives diplomatiques). 9 novembre 2012. Avantpropos de Frédéric Baleine du Laurens. Bruxelles, P. I. E. Peter Lang, coll. «Diplomatie et Histoire ", vol. 20, 2013, 264 p. Notes, bibliographie, illustrations hors texte. 
1 Le cinquantième anniversaire de Vatican II voit, bien sûr, les colloques se multiplier. Celui dont les actes sont ici publiés, consacré à Vatican II vu au prisme de la France (archives, diplomates, acteurs), s'inscrit dans un ensemble de travaux étalés sur quatre ans, sous la direction de l'équipe RESEA du LARHRA. L'introduction de Bernard Barbiche et Christian Sorrel l'expliquant très bien et présentant les onze communications et la conclusion, le recenseur se trouve quelque peu piégé. Aussi s'attachera-t-il à recomposer selon ses centres d'intérêt les fruits qu'il a tirés de ce colloque.

La diplomatie française a beaucoup ausculté Vatican II. Nicole Even («Les sources de l'histoire de Vatican II dans les archives de la présidence de la

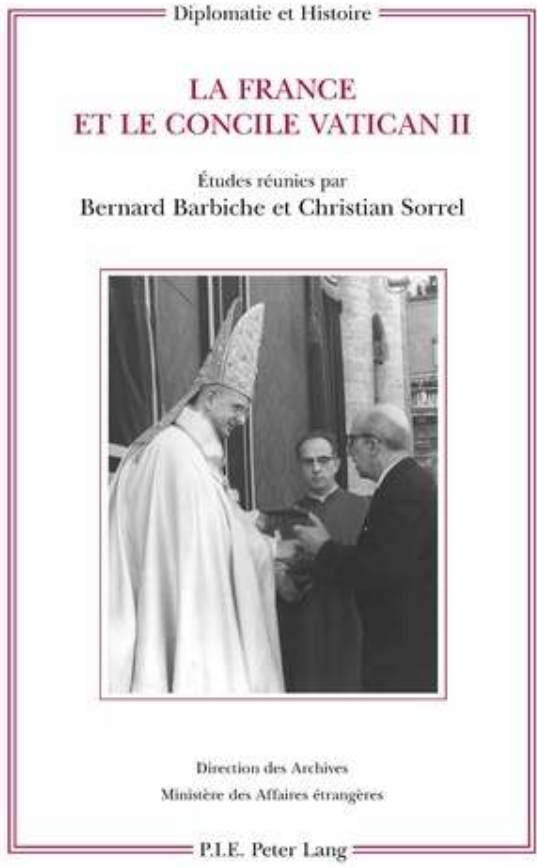
République»), François Falconet («Les sources de l'histoire de Vatican II au ministère des Affaires étrangères ») et Jean-Dominique Durand ("L'ambassade de France près le Saint-Siège et le concile Vatican II ») le prouvent excellemment. Les archives du ministère des Affaires étrangères regorgent de pièces fort diverses dans des fonds très variés, montrant que l'observation se fit à de multiples échelles. Le concile devient ainsi un "champ d'étude foncièrement multilatéral et international », car chaque service avait "des intérêts particuliers » « en fonction de [ses] attributions et problématiques du moment » (F. Falconet, p. 33-34).

3 Le regard diplomatique est souvent politique: quelles implications des positions concilaires sur la politique nucléaire française (p. 25), les puissances soviétisées et les relations internationales (la coexistence pacifique en DDR, p. 24). La politique, soit les intérêts de la République, oriente aussi l'attitude des ambassadeurs de France près le Saint-Siège de 1962 à 1965. Faire de la villa Bonaparte un centre de rassemblement des Pères et experts français et francophones pour « soutenir une Église considérée comme dynamique et l'aile marchant du catholicisme » (J.-D. Durand, p. 76) est le souci de Guy Le Roy de la Tournelle (1959-1964) et René Brouillet (1964-1974). En effet, appuyer les Français au sein de l'Église, c'est développer l'influence française dans le monde - la laïcité y trouve aisément son compte, puisque l'ambassade poursuit ce qu'elle fait depuis son rétablissement en 1921. D’une certaine manière, l'Église de France et la France sont commutatives, au moins pour les hommes politiques, et, à lire Philippe Levillain («Rome et la France de Pie XII à Paul VI»), aussi pour les papes - et peut-être également pour les historiens. Comment ne pas souligner alors la permanence d'une forme de gallicanisme étatique, toutes choses, mêmes religieuses, devant être rapportées à la modernité politique qu'est l'État-nation ? Cela ne dilue pas pour autant la perception de la spécificité du fonctionnement du catholicisme. Car, même si le concile est appréhendé en termes politiques (rapports de force entre majorité et minorité), les ambassadeurs soulignent la particularité de ce que P. Levillain, jeune 
normalien et bénévole attaché de presse à l'ambassade de septembre à décembre 1965 (p. 63), appellera la « mécanique politique de Vatican II ».

4 La politique, soit la dynamique des rapports de pouvoir et d'autorité entre les hommes, guide donc les analyses. Il en va de même chez les acteurs du concile. Acteurs par le récit, d'abord, que sont les "grands chroniqueurs français du concile" (Congar, Rouquette, Laurentin, Fesquet, Wenger) finement étudiés par Yves Poncelet, qui, disons-le de manière un peu brutale, lisent l'assemblée dans des termes que la Convention n'aurait pas reniés (le "marais", entre les tendances conservatrice et réformatrice, est frappant, p. 98), alors qu'eux-mêmes sont des observateurs fort engagés. Acteurs, ensuite, par l'action que sont les Pères: le cardinal Tisserant, qui, Étienne Fouilloux le rappelle, en raison de son expérience des catholicismes orientaux, est le mieux au fait, au sein de la Curie, voire des pères, de savoir ce qu'il est possible d'attendre d'une assemblée aussi complexe qu'un concile (ce qui ne l'empêche pas d'appuyer la majorité); Mgr Garrone, Français romanisé puis gallicisé, pour lequel Christian Sorrel montre excellemment que le concile fut une école accélérée d'exercice des relations de pouvoir au point de lui ouvrir une carrière curiale. Acteurs, encore, par la réflexion, que sont les experts: le p.Congar, qui bénéficie du changement impromptu des règles politiques du concile à l'ouverture de celui-ci, mais qui est loin d'avoir le goût de la manœuvre, même s'il entend faire avancer ses idées (communication d'Eric Maheu); le p. de Lubac, qui ne sut ou ne voulut jamais être un politique de la mystique, si ce n'est par le biais de l'aura intellectuelle, ce qui le conduit à l'angoisse au fur et à mesure des sessions, car son aura n'est pas (plus ?) celle qu'il aurait voulu (communication de Loïc Figoureux). Acteur singulier, enfin, l'observateur Jean Guitton, dont Philippe Chenaux montre qu'il participa bien volontiers à la politique personnelle de Paul VI - peut-être au profit de sa propre politique : son autopromotion. Si donc la politique est partout, il faut conclure avec Michel Fourcade et son "Vatican II dans le débat théologico-politique français", qui bascule vers une conception de la politique comme le rapport entre les pouvoirs institués. De manière stimulante, il avance que l'Église catholique, avec Dignitatis humanæe, transforma unilatéralement ses relations avec les parties prenantes du théologico-politique, l'État, la Magistrature et l'Université. En particulier, ne reconnaissant plus de rôle à l'État dans l'accès au salut, le réduisant à une fonction instrumentale au sein de la société, elle le désacralisa et le laissa dépité et troublé.

5 Faut-il en conclure que Vatican II apparaît alors comme un concile cléricalo-centré ? La découverte et la pratique des joies des arcanes politiques durant les sessions et intersessions, autour de débats et d'enjeux théologiques, auraient conduit les Pères, experts, observateurs et chroniqueurs à rapporter ceux-ci, sans s'en rendre compte, à un conflit intraecclésial de pouvoir. Le trait est sans doute forcé. Mais est-il si inexact ? À voir les réactions des traditionalistes au concile, dont The Rhine [flew] into the Tiber (P. Ralph M. Wiltgen, 1967- édition française en 1973), qui dénoncèrent rapidement les complots de coteries progressistes (voire pire) et vitupérèrent contre les faillites (voire forfaitures) de l'autorité magistérielle, et grands absents de ce colloque alors que la France fut un (un, non le seul) des principaux espaces de la contestation traditionaliste, on peut poser cette question. 